\section{Ethical Lingua}

Journal of Language Teaching and Literature

ISSN 2355-3448 (Print)

ISSN 2540-9190 (Online)

Volume 5, Number 1, February 2018

pp. $39-60$

\title{
Analyzing Advertising Specimen within the Scope of Circumstantial Choices: A Case Study of Airtel尺 Advertisements
}

Taofeek Olaiwola Dalamu

lifegaters@yahoo.com

University of Lagos, Nigeria

Received : 05 September 2017; Accepted : 20 January 2018

DOI : https://doi.org/10.30605/ethicallingua.v5i1.634

\begin{abstract}
This study focused on the Airtel's Always On slogan to elucidate alternating choices constructed to build strong relationships with subscribers. The proceeding semiotic paradigms were strategic discourses communicated to dominate some facets of human endeavors serving, perhaps, as signals to operational capacities of Airteß $\mathbb{R}^{\circ}$. Halliday's concepts of the Paradigmatic Order and Circumstantial facilities of the Transitivity system were applied to seven ads of the Always On to assist in deriving both structural and semantic values from the switching linguistic elements. Tables and a graph provided supports for the analysis as indicators of the recurring components of the analyzed structural choices. The study showed that Always On is synonymous with Airtel in terms of operational consistency. It revealed further that creativity was not limited to the phrases proceeding Always On but that the choice inventions were extended to background images playing supportive roles in the persuasion. The Circumstantial functioned as cause, manner and role with reliable service provisions. The switches provided recipients avenues to generate diverse meaning potential that could naturally stimulate individuals to consumption. The study concluded that the alternating devices did not only fascinate persuasion but also demonstrated systemic creativity of enlightenment.
\end{abstract}

Keywords: advertising appeal; circumstantial; paradigmatic order; semiotic; syntagmatic order 
Dalamu:

Analyzing Advertising Specimen within the Scope of Circumstantial Choices

\section{Introduction}

There is no doubt that since the inception of cell-phones provision for throngs of the Nigerian populace, the telecommunications (henceforth: telecoms) providers have been working effortlessly to persuade consumers to patronize their goods and services. Airte $\AA^{\circledR}$, in many ways, has branded and rebranded the products so that the firm can sustain its market value and share. In the course of persuading subscribers to be loyal to the products, Always On has been adopted as a rebranding winning strategy to maintain the existing relationships. Always On as a mantra could be classified as an enigmatic tool capable of making Airtel a consistent and constant phenomenon in the Nigerian telecoms industry. While the other competitors might go off the air probably for some hours, the Airtel airwaves cannot avoid going off air for a micro-second. This is because Airtel projects itself as always on, no matter the challenges at hand. In respect of that, the concept of Always On is schematized as a winning strategy, as earlier stated, for Airtel in the telecoms business environment.

Advertisement (henceforth: ad) is a virile tool, which manufacturers understand that its employment can greatly influence the decision of the public in patronizing their goods and services in the competitive market (Myers, 1994). It is probable that the new generation of consumers' needs much more to get convinced enough before individuals can buy the manufacturer's products due to global economic challenges. Companies have tended to appeal to consumers to buy their products with certified guarantees of their products. It may be painstaking for manufacturers to create a special need for their product in order to persuade consumers. Many firms can further publicize the products aiming at manipulating the purchasing decision of the target audience in so many ways. The study has chosen slogan of Airtel's Always On in Nigeria as a case study for such business decisions and behaviors. The services and products that Airtel provides for the Nigerian people may have not changed. Nonetheless, the clichés are rather presented in a new form as a reengineering strategy of sensitization. Airtel introduces a new range of ads for similar products in a new way to reenergize the loyalty of subscribers and to woo new consumers.

One can emphasize that every individual is in need of certain things, and most especially basic necessities of life such as food, shelter and clothing. The advancement of the world, one could further reiterate, has mounted pressure on every individual to desire in life more than the orthodox basics of food, shelter and clothing. Apart from some places in Nigeria where electricity is not constantly available, virtually every Nigerian might desire to have a mobile telephone as a necessity as well as a means of belonging to a particular class of people. With this view, a mobile phone seems to have become a basic need like food, shelter and clothing. Perhaps, advertisers have perceived the love of people for telephone as a golden opportunity to take advantage of. So, the 
product campaigners tend to arrest this deep-lying desire or yearning for a mobile phone. This is achieved by deploying ads to appeal to the individual's passion. Sometimes, manufacturers are not comfortable to folding their arms to depend on the yearnings of consumers. The ritual of advertising is consistently performed as a predictable business culture. It is through that motivation that the author has examined the alternating choices in the selected ads of Airtel's Always On. The objective is to reveal the alternating semiotic paradigms/choices adapted to campaign for the Airtel's products or services.

\section{Advertising Appeals}

Human beings are naturally emotional (Plutchik, 2001). Emotion is contextualized here as anything that generates a sort of feelings on a matter. Human emotions, among other things, are expressed in love, joy, and several behavioral and psychological attitudes (Matsumoto, n.d.). Ad professionals desperate to sell their products have also noted that human beings in the global race of consumerism are attune to emotional engagements in assorted degrees, yet, they might be reluctant in giving ads the necessary attention (Cook, 2001, p. 1). Advertising campaigns are resisted because the persuasive activities might not be making meanings to some people. Sometimes, recipients rather classify ads as being disturbance and irritant to their precious lives. The emotions of the individual could be considered as fertile land for launching and growing goods and services with expectations of good harvests. Advertisers key campaigns into the strong emotional intensity observed in the public glare to construct momentous messages that can appeal to consumers. Then, communications created between the products and the audiences are expressed through emotional appeal in a positive light to arrest the audience's interest.

Particularly, Fowles (1998, p. 2) argues that "Human beings, it is presumed, walk around with a variety of unfulfilled urges and motives swirling in the bottom of their minds. Lusts, ambitions, tenderness, vulnerability - they are constantly bubbling up, seeking solutions." The urge in people to have particular things that can enhance their standard of living, in Fowles' point of view, is primal. The instinctive urge differs, grows and increases as the individuals grow and are exposed to beautiful and captivating things in this life of expectancy. The assistance that advertisers render is to appeal to consumers' lustful urge in order to proffer solutions to their desires. Signs are strategically fabricated in the ads to serve as a point of contact, conviction and command. These semiotic alternating choices appeal to people's mental imaginative attitude, as Long-Yi (2011) observes, with a sole objective of creating a tremendous drive towards the products. Emotion seems to guide human thoughts and, perhaps, such passion is more or less important than most ad professionals realized its weight. Hollis (2010) explains that the initial instinctive response of the consumer determines three things: "how much attention we will pay to the event that triggered it, what 
Dalamu:

Analyzing Advertising Specimen within the Scope of Circumstantial Choices

our conscious response will be, and how deeply our memories of the event will be entrenched" (p. 1-2). According to Hollis, the representation of an ad that seeks the attention of the consumer and creates a conscious response must be easily memorable.

In Leech's (1966) earlier sense the first proposition of Hollis (2010) can be achieved by communicating in selected images, by presenting shocking and unexpected codes or by involving unconventional linguistic behavior. These might sometimes violate conventional rules which are perceived as mesmeric and geared the attention towards a product or service. Second, the feelings that any ad creates in the subconscious may not be seen or expressed by consumers. Yet, the selling power achieved could explain the effect of advertising on consumers. This serves as an indicator that the essence of advertising is principally to create an enormous selling power for the product. The features of a product seem to be always positive without a faint line of negativity. Third, emotion is deep-rooted in the target audience with the lasting potential impression that advertising creates as the wit for the public (p. 27). One of the significant functions of an ad manager is to create constructs as recurring objects that have the capacity to attract as well as influence readers. In that wise, puns, short puzzles, simple dictions, repetitive coinages and pungent structures become relevant facilities in the field of persuasion. The name and image of the product, as well as the name of the company could be boldly embroidered; else nothing seems to have been campaigned in the ad. In corollary, Fowles (1998) claims that;

Most advertisement appearing in national media can be understood as having two orders of content.

The first is the appeal to deep-running drives in the minds of consumers. The second is information regarding the goods or services being sold: its name, its manufacturer, its picture, its packaging, its objective attributes, and its functions (p. 3).

Two points of reference, Fowles explains, characterize the centrality of ads on products. These are: the target audience's desires and the characteristic attributes surrounding the products. A product's ad is shaped around the desires of the target audience; and why doing this, the introduction of the information about the goods and services is hugely presented. The two contents seem to be exemplified simultaneously. The appeal in the ad builds an emotional connection between the target audience and the advertised product for the purposes of attraction and mobilization (Dalamu, 2017a). The connections between the two entities are resourceful because language evolves powerful emotion that has judgmental impact on people (Glenberg \& Rink, 2007, p. 1). The emotional appeals are strategically designed and varied to suit the goal intended. The communicative discernments, as remarked, usually operate in certain degrees of influence. 
Scholars including (Khan \& Sindhu, 2015) have categorized advertising appeals into several taxonomies. There are other scholars who have classified advertising appeals differently. Ambekar (2009) argues that advertising appeals could be distinguished into rational and emotional in which other appealing elements are in operation. Patidar (2012) otherwise articulates that advertising appeals are of three categories, namely, rational or informational appeals, emotional appeals and moral appeals. In the suggestion of Mohana (2014) the explication of advertising appeals operates within seven typologies. Irrespective of the views of scholars in this regard, advertising appeals could be numerous as advertising itself is a shameless genre capable of making use of any material that can assist advertisers to accomplish their dreams (Cook, 2001, p. 3). From the chessboards of scholars on advertising appeals, it is significant to highlight some of the appeals. These are, romance or sex appeal, music appeal, rational appeal, adventure appeal, youth appeal, bandwagon appeal, fear appeal, emotional appeal, scarcity appeal, humor appeal, and aesthetic sensational appeal (Fowles, 1998, p. 4; Ambekar, 2009, p. 2-4; Patidar, 2012, p. 1-3; Mohanan, 2014, p. 1-2).

\section{Semiotics in Advertising}

The influential potency of semiotics could be centrally imperative when one discusses ads' spectacular successes. The predominance of semiotics in ads is as a result of the role of the advertising industry's captivating constructs play in signification (Combe, Crowther \& Greenland, 2003). Perhaps, there is a possibility that in situations where texts (words) are not sufficient to serve as signifiers to the public, semiotics (images) will be preeminent. Semiotics is supreme in decoding meaning from anything that represents something else in a specific capacity. Analysts interpret entities, Chandler (2012) asserts, as signs largely unconsciously by correlating them to familiar system of convention (p. 12). It is the meaningful use of signs that is the hub of the concerns of semiotics. Individuals are capable of construing meaning from the social ideology within their context. The socio-cultural ideology of consumers is presented in an ad frame in the combination of colors, texts and images to sensitize the audience. Variations of cultural norms propel the advertisers to employ semiotic materials that can communicate the intended message to the public in order to build a social relationship between the advertised product and the public (Dalamu, 2017b). Such spheres may influence consumers to generate a sense of emotional concern for the product.

That recognition motivates Brown and Miers (2009) to state that "Not only do companies use semiotics to sell their products, but they also target specific audiences based on their claim, gender and age, etc. in order to sell their products" (p. 1). This view indicates that haphazard applications of semiotic codes could be messy and chaotic if the arrangements are not structured in 
Dalamu:

Analyzing Advertising Specimen within the Scope of Circumstantial Choices

accordance with the people's cultural values and exposures. Most ads are organized with the focus of a particular member of the public in mind. The target audience can be influenced through the matter of age, sex, profession-wise, education, class, etc. The specificity of the ad in relation to the audience gives a sense of belonging to an individual looking at the ads in order to conform to its message. For instance, there are many gradations located in the Airtel's Always On ads. The series of Always On focus football lovers/players, women on shopping, students, youths, music lovers, travelers, etc.

Semiotics, having its operations felt in most advertising communications (Williamson, 1978), has attracted numerous theoretical and experimental analyses with considerable global impacts (Opeibi, 2009, p. 142-145). Magalhães (2005) critically studies the notion of hybridity in gender identity as positioned in several ads in Brazil. The individual links how ads positioned the public ideologically in the manner of interchangeability where self is constructed. Magalhães adds that "at present, as a result of intercultural relations caused by migration, these fixed identities have given ways to mobile, hybrid identities" ( $p$. 3). This seems a socio-contextual representation amalgam where advertisers incorporate sexual subjects to attract the target audience. The impact of the synthesis might be enormous. This is on the ground that the communication depicts common knowledge and ideas that are practicable. The hidden voice advocates the semiotics represented in the ad. Enthralling images in the ad frame seems supreme to play a dominant role in constructing the expected meaning for the public. Magalhães experimentation shows that there is a natural co-existence between men and women as represented in the ads which characterized post-modernization. Women bodies, in Magalhães' (2005) conclusion, are commodified to represent freedom, beauty and romantic intoxicant. Men are seen as preferred sites for dynamism that can powerfully control situations.

Stone (2000) extends semiotic study by doing an analysis on designer clothing ads. Stone's approach predicates on images rather than the combination of texts and images. The ad frame contains no texts except the logical emblems as the signatures of the fashion designing companies. According to Stone (2000), the ads do not only attempt to sell to the public the clothes, but also a future image of ourselves as more desirable, happier, and representations of everything the reader desires to become (p. 3). The intention of the advertisers is to create feelings, moods, and characteristic attributes from a vague object to an extent of drawing a parallel between it and the concrete. In that light, the interchangeability provides a promissory note of assurance of getting and enjoying certain benefits that must be derived from the product. Stone submits that dresses are signifiers of systematic organisms that communicate messages and deep meanings to the target audience. Among others, the designer clothes are said to evoke angelic impressions, naturalness, 
freedom, purity and innocence on readers. The materials also create an impression of independence and class, which breaks the wearer away from the cage of convention to innovativeness assisting the individual to escape the boredom of conformity. Stone's result further demonstrates the distinction seen in special people. The world of hard labor and the luxury of fashion are separated with the appearance of the models which suggests an imposed authority in a romantic mood that demands attention.

Adedun and Hammond (2013) examine the semiotic system in the marketing communication campaigns in the billboards of Nigeria and Ghana telecoms providers. The relationships between semiotics and semiotic resources; and culture are entities of analysis. In the study, the language and semiotic resources in billboards ads are usually positive and persuasive (Adedun \& Hammond, 2013, p. 4). To achieve the persuasion, the investigators stress that celebrities are engaged as expressions of satisfaction and fulfillment. In the findings, there is commonality of utilization of cultural resources in the construction of the billboards. Despite the significant nature of these studies Magalhães (2005) in Brazil, Stone (2009) in the United Kingdom, and Adedun and Hammond (2013) in Nigeria and Ghana - it is striking to notice that none of these studies examined semiotic texts and images from the point of view of the Paradigmatic Order. However, this study prides itself, as stated earlier, on the investigation of semiotic alternating choices in the Airtel's Always On ads in Nigeria.

\section{Theoretical Configuration}

\section{Paradigmatic and Syntagmatic Axes}

Discussing the concept of paradigmatic system without a reference to the concept of Syntagmatic chains can generate unending arguments in linguistic realms. This is because it is very slim to explain the paradigmatic axis of a system without recourse to the syntagmatic structure. The syntagmatic seems to be dominantly fundamental in a text and at the same time, the chain is the custodian of the paradigmatic relations. That pinpoints syntagmatic organization as the revealer of the speaker's chain of exchanges during interactions. The paradigmatic choices of a writer or speaker provide the Syntagmatic organization known as syntagm. The two kinds of relations embedded in linguistic signs, according to Stubbs, are syntagmatic axis and paradigmatic axis (Stubbs, 2002, p. 211-215). The paradigmatic axis explains the relations of signs in an opposition. Dyer (2005) comments that, "syntagmatic relations are the permissible ways in which elements succeed each other or combine together in a chain of discourse. These elements have nothing in common and are brought together by virtue of combinatory syntactic rules" (p. 126). The notion of the syntagmatic axis is a derivative of the clause - simple or complex forms. 
Dalamu:

Analyzing Advertising Specimen within the Scope of Circumstantial Choices

A syntagm is simply described as a sentence. It is a linguistic unit consisted of a set of linguistic forms (phonemes, words, or phrases) that are in a sequential relationship to one another, and always composed of two or more units. The syntactic thought is that the combinations of classes of word to produce meaning potential are based on societal norms. The system is organized in linguistic conventions empowered by its context. However, the units cannot be formed in a disorganized or unsystematic pattern else the decoding of the structural signifiers might not produce substantial signified. One could further attest that a syntagm is the combination of interacting signifiers, which form a meaningful whole within a system. In language, a sentence is a syntagm of word, so it is also paragraphs and chapters. A larger syntagm is composed of smaller syntagms with interdependence between both. Syntagmatic relations are the various ways in which elements within the same text may be related to each other. In other words, syntagms are made up of symbolic elements, each independent in meaning but transformed into lexicogrammar (Matthiessen, Teruya \& Lam, 2010; Halliday \& Webster, 2003) when combined into a whole.

Relations are built in a syntagm when the signs are combined as the socio-cultural system of society. Eggins (2004, p. 190) buttresses the argument by saying that "Syntagmatic relations, relations along the axis of chain, are relations by which signs can go together in sequences or structures, then the relationship between one sign and the signs that go before or after it." The sequential signs regiment from the left to the right as observed in most languages of the world; English, French, Yoruba, etc. They form linguistic items functionally and horizontally in the $x$-axis as conceptualized in Figure 1. Other characteristics are that the structural codes possess combinatorial possibilities and they collocate in meaning productions. Linguistic principles guide the meaningful substance obtained from the syntagm's linear disposition or arrangement of a discourse (Yule, 1985).

Paradigmatic relations are the underlying relations found in pre-existing sets of signs with workable alternatives. A change in one sign by replacing it with another sign might resort to changes in the signified (Fontaine, Bartlett and O'Grady, 2013). Chandler (2012) argues that "Paradigmatic relations are the oppositions and contrasts between the signifiers that belong to the same set from which those used in the text were drawn" (p. 76). The relations of oppositions and contrasts can be featured and drawn from the perspectives of synonyms as well as antonyms (Halliday \& Matthiessen, 2014, p. 18-32; Bloor \& Bloor, 2004, p. 3-4, 236-7). Paradigmatic relations also function in the phonological minimal pairs of phonemes that produce contrastive distinct meanings (O'Grady, Dobrovolsky \& Aronoff, 1991, p. 55-6). The concept of affixation - prefixes and suffixes - oriented in morphological domain expresses Paradigmatic-Systematic Order (Yule, 1985, p. 60-1). The grammatical rank scale is another perspective that appreciates paradigm functions. A phrase, a 
group or a circumstantial element in a clause of Transitivity could be used to exchange one organ with another in order to create a shift in meaning (Thompson, 2004, p. 109; Martin, 1992, p. 154; Butler, 2003, p. 368; Ravelli, 2000 , p. 32). Dyer (2005) strengthens this notion by describing Paradigmatic relations as those linguistic activities that belong to the same associative set of virtue of the function that they share. So, a sign is in a Paradigmatic relation with all the signs which can also occur in the same context but not at the same time (p. 127). Dyer's point of view discerns Paradigmatic elements as independent until such functional organs partner with other linguistic segments for meaning derivatives. The elements are usually substitutable. It means that those structures involved cannot function at the same time in a semiotic stratum. This is unlike the syntagmatic relations where the concerned elements are dependent and also operated together in a semiotic ideological practice. As rightly observed, the Paradigmatic Order is what goes instead of what (Halliday \& Matthiessen, 2004, p. 22; also in Halliday \& Webster, 2005a).

From a technical orientation, the paradigmatic order is seemingly a system of choice in a vertical axis, that is, the y-axis demonstrated in Figure 1. Therefore, the paradigmatic analysis explained examines each of the alternating signifiers/choices utilized in the Airtel's Always On ads, which have been chosen in a similar situation. The common ground of the operation of the context is Always $O n$ in which all the Circumstantials are predicated on. In addition, the study also considers the significance of choices made in the ads. The diagram shown in Figure 1 below is a simple analogy illustrating the syntagmatic and paradigmatic relationships.

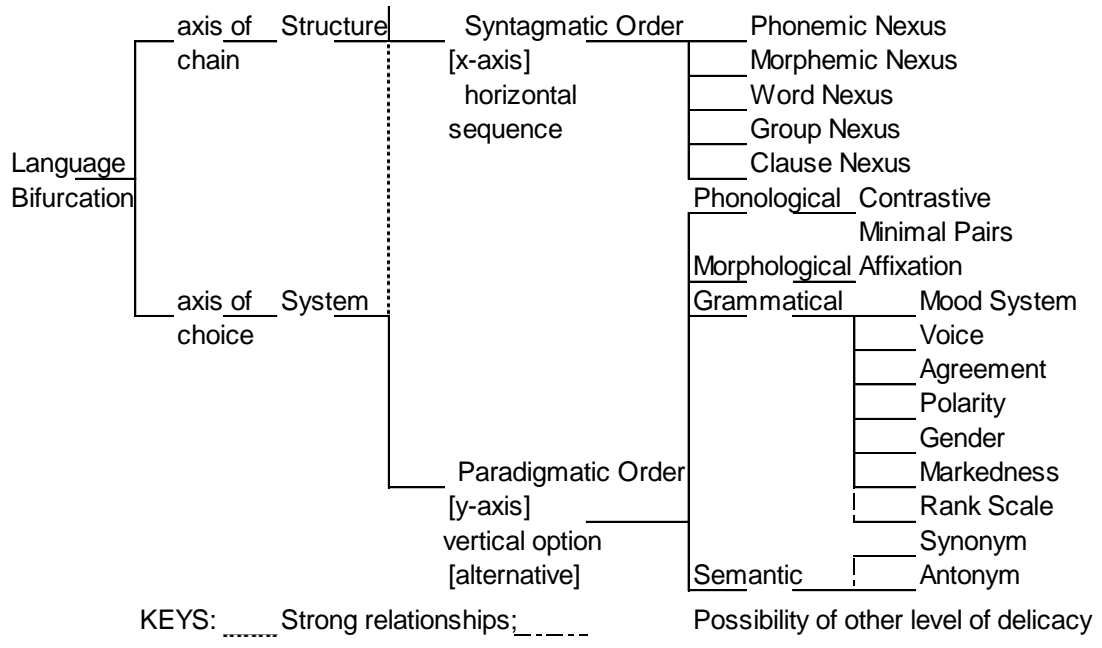

Figure 1. Syntagmatic and Paradigmatic Relationships

Figure 1 indicates language as operating within two linguistic parameters. That is, the axis of chain and the axis of choice. The axis of chain represents the structure of a text whereas the axis of choice is the system accompanying the grammar of a text which has the clause as the center piece of functional 
Dalamu:

Analyzing Advertising Specimen within the Scope of Circumstantial Choices

operations. However, there is a conjugal but a linguistic tie between the structure and the system. Figure 1 demonstrates the unbroken relationship with a vertical-hatched line.

\section{Circumstantial Elements}

The core of the Hallidayan grammatics (i.e. theory) is tacked to the three metafunctions - ideational, interpersonal and textual metafunctions. These triadic metafunctions also function in a text as a means of generating full meaning potential (Thompson, 2004, p. 30; Halliday \& Webster, 2005b). The intention of this article is not to flex muscles in applying the three Metafunctions, not even to fully apply just one of them. The author applies only one-third of the transitivity system. The investigation attempts to solely predicate on circumstantial as represented in the Airtel's Always On ads exemplified in Figure 2 below. Transitivity, the grammatical transpose of the ideational metafunction, is divided into participant, process and circumstance (Ravelli, 2000). The type of process experienced in the clause determines the participants. The process dictates the participant(s) for certain participants who have been nip in the bud for certain processes. Halliday (1994) highlights six processes existing in the English language (also in Halliday \& Matthiessen, 2004, p. 172-3; Eggins, 2004, p. 213-4).

Besides, some clauses may have circumstantial elements, which provide more information about the participating entities in a clause. Circumstances are mobile. That is, they are characterized to function in the beginning, middle or end of a clause. Thompson (2004, p. 190) states that circumstances are 'realized by Circumstantial Adjuncts, essentially encode the background against which Process takes place. Circumstances tend to connect the Process and Participants together. They also have the privilege of operating freely in all manner of Processes (Fontaine, 2013; Bloor \& Bloor, 2013; also in Halliday \& Webster, 2009). Circumstances have been categorized as per functions. Some of them function as enhancing, extending, elaborating and projecting (Halliday \& Matthiessen, 2014) with their types in variance.

\section{Method}

During the data collection regime, one observed that the Airtel's Always On ads were scarcely solely positioned in the newspapers, signboards, as well as the Internet. Efforts were made to search these entities for the required ads in various numbers. In the three domains, about thirteen Always On ads functioned with several discrepancies. From these the author selected seven ads with correlating traits of the study's intention. They are labeled below with $A D 1-A D$ 7 indicators. The concepts of Paradigmatic Order and Transitivity inclination from the Hallidayan School were the tools of analysis. The study considered facilities of the grammatical level as tools of analyzing the texts. The phonological, 
morphological and semantic applications are out of the scope of this study. As well, the Participant and Process in the Transitivity system are deliberately aborted in the analysis because they have no connections with the study. The most relevant sub-concepts in the Paradigmatic system, as shown in Figure 1, are the participants and Circumstances of the Transitivity system. It is worth-mentioning that the Paradigmatic Order and the Circumstantial of the Transitivity system are entwined as an indivisible device of the analysis. Figure 2 exemplifies such relationship in the alternating form (Paradigmatic way) that the Circumstantial structures recur in the seven ads. In addition to that exposition, Always On, as the Participant, retains its operational status by playing a domineering role in each of the constructs. By that, one could infer that Always On seems a chameleon that attracts Circumstances with different functional elements. Invariably, the changes create different meaning potential that could excite consumers. The applications of those devices are featured in both the analysis and discussion.

The study presents the texts of the ad frameworks below as appeared in the communication plates. The analyst positions the plates in the discussion section based on the relevance of each of the entities to the segments. The texts are:

AD 1: Always on smartest network for your smart phone

AD 2: Always on with destination news

AD 3: Always on with latest trends

AD 4: Always on with social media

AD 5: Always on with latest tunes

AD 6: Always on with instant knowledge

AD 7: Always on to live results.

\section{Data Analysis}

The analysis in Figure 2 explicates the application of the Circumstantial to the Airtel ads.

\begin{tabular}{|ll|l|}
\hline Always on $\quad$ smartest network & for your smart phone \\
\hline & & Circ: Cause \\
\hline
\end{tabular}

\begin{tabular}{|l|l|}
\hline Always on & with latest trends \\
\hline & Circ: Manner \\
\hline
\end{tabular}

\begin{tabular}{|l|l|}
\hline Always on & with social media \\
\hline & Circ: Manner \\
\hline
\end{tabular}

\begin{tabular}{|l|l|}
\hline Always on & with latest tunes \\
\hline & Circ: Manner \\
\hline
\end{tabular}

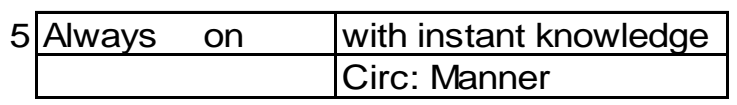

\begin{tabular}{|l|l|}
\hline Always on & with destination news \\
\hline & Circ: Manner \\
\hline
\end{tabular}

\begin{tabular}{|l|l|}
\hline Always on & to live results \\
\hline & Circ: Role \\
\hline
\end{tabular}

Figure 2: Analysis of the Airtel's Always On Texts 
Dalamu:

Analyzing Advertising Specimen within the Scope of Circumstantial Choices

The study later reports the fundamental domains of the application of the Circumstantial devices in Table 1 and Figure 3. The goal is to calibrate the recurrence(s) of the Transitivity elements in the ads' texts.

\section{Results}

The first observable factor in the analysis in Figure 2 of the seven Airtel ads is the Always On construct that is common to the structures. It is upon the sustained structural Participant that the other Paradigmatic alternatives/choices rest. Indirectly, the steady device, Always On, has become a point of departure for the other linguistic organs despite the fragmentation of mood system of Subject and Finite.

Moreover, the investigation translates Figure 2 into Table 1 below to demonstrate the functions of the elements in the semiotic slots in a digitized form

Table 1. Digital Representation of the Airtel's Always On Structures

\begin{tabular}{|lllllllll|}
\hline CIRCUMSTANTIALS AD1 & AD2 & AD3 & AD4 & AD5 & AD6 & AD7 & TOTAL \\
\hline Cause & 1 & 0 & 0 & 0 & 0 & 0 & 0 & 1 \\
Manner & 0 & 1 & 1 & 1 & 1 & 1 & 0 & 5 \\
Role & 0 & 0 & 0 & 0 & 0 & 0 & 1 & 1 \\
\hline
\end{tabular}

The illustration of the table and graph in Figure 3 further summarizes the digitized nature of Airtel's Always On structures shown in Table 1 above.

\begin{tabular}{|ll|}
\hline CIRCUMSTANTIALS & VALUE \\
\hline Cause & 1 \\
Manner & 5 \\
Role & 1 \\
\hline
\end{tabular}

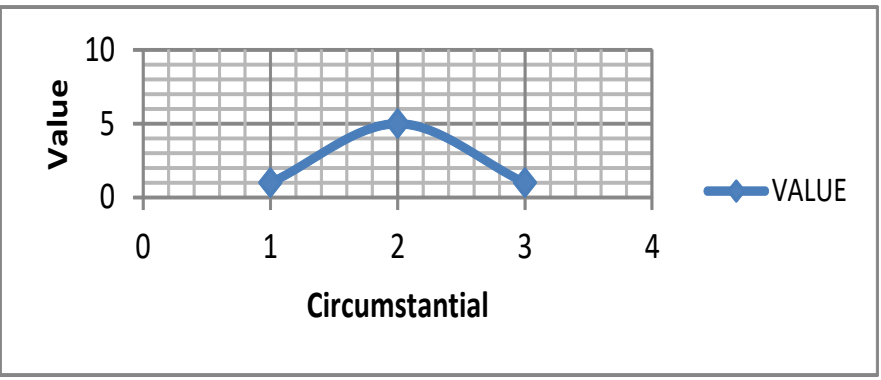

Figure 3. Summary of the Airtel's Always On structures

As elucidated in Figure 3, the Circumstantial of manner records the highest application in the Airtel's Always On Paradigmatic structural Order. Cause and role, as choices, occur just one time each. These operations signal that the ads concentrate on constructing a viable relationship between Airtel packages/services and consumers most times with the structural choices of manner in order to stimulate persuasion. The facilities of the enhancement provide additional information to subscribers which happened to be the hub of the messages, e.g. with latest tunes. 


\section{Discussion}

As a norm, the letter $O$ in the $O N$ of Always On communication facilities encapsulates unique symbols in all the ads. These symbols indicate telephone, shopping basket, social media, musical tune, lighting (bulb), aircraft, and football. There is no negative polarity in all the texts. Nevertheless, the elements, the researcher could constitute as declarative constructions within the mood system made up of active voices. Within the grammatical rank scale, the texts are presented as elliptical clauses that contain Circumstantial elements of divergent nomenclatures. These choices are for enhancement, projection and elaboration providing required information for the audience. It is in the quest of these campaigns that the Paradigmatic choices come to be realized with the modest establishments. The ads feature three semiotic components - texts, images and the pictures to synchronize the message. Always $O n$ is the sustainable background of all the texts. It represents a general term, which serves as a marker to the erratic punctuated clauses.

Besides, the catch-word accommodates other Circumstantial elements of cause, manner and role as shown in Figure 2. Always On on its own accord is an adverbial of time seemingly operating as Participant. Probably, Always On could be seen as a symbol of trademark that the Airte/ telecoms has informally adopted. The combination of always plus on could further be classified as an adverbial group in an exaggerated emergence. The appearance of the adverbials points to the fact that Airtel network possesses a permanent domain in the league of the Nigerian telecoms industry with never-ending signals that enrich the lives of consumers in varieties of ways. Another indicator of Always $O n$ is to present itself to the public as a network that is always available with immense benefits to users. The only phenomenon that is latent to terminate the technical assistance that the Airtel network pledges and provides for consumers might be dead.

Besides, AD 2 - AD 7 contain the imperative dial *401\# to activate as a tool of persuasion. Understanding the antics of advertisers for what they are, one can mention that the mission of advertising might not be fulfilled until the target audience patronizes the advertised products. The maxim, Always On, and the pictures in the ad frames are elements of attraction for the understanding of the intended message. After the enticements through both textual and pictorial devices, consumers are enjoined to dial ${ }^{*} 401 \#$ in order to activate any of the Airtel packages. The mission of the advertising expert is only accomplished when the public swing into action by consuming the advertised goods and services. That is the reason for motivating subscribers through dial * 401 \# to activate the presented services for enjoyment as shown in all the ads' frameworks. Furthermore, the analyst expounds the seven Circumstantials through the insights of Halliday (1994), and Halliday and Matthiessen (2004). It is that perspective that the study constructs the alternating idea as Systemic Device (henceforth: SD). 
Dalamu:

Analyzing Advertising Specimen within the Scope of Circumstantial Choices

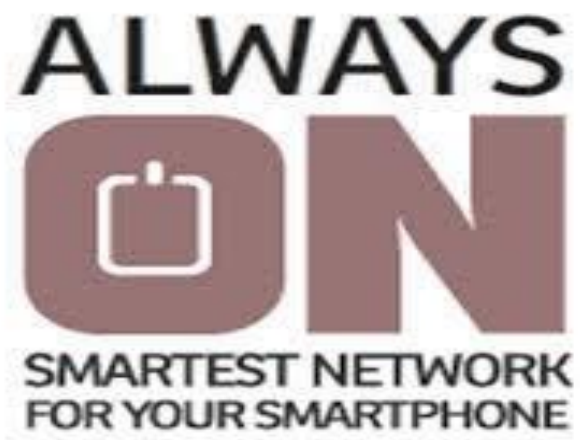

AD 1

The advertiser of Always On targets a particular class in each of the ad frames. Such consumers are students, youths, music lovers, women on shopping activities, ladies, social media enthusiasts, football lovers, internet appreciators, travelers, etc. The propagation is a calculated attempt to lure every Nigerian into any of the classified groups. AD 1 employs a comparative strategy where the Airtel network is considered as the smartest in two distinct ways. Thus, one could argue that: One, Airtel is the smartest network among its equal competitors in the telecoms industry. Two, it is also smarter than the consumer's telephone because the consumer's telephone taps resources from the network. The preposition, for, is the marker of the performance enhancement in the fragment. The Circumstantial for your smartphone projects cause which functions as purpose.

$\mathrm{SD}=$ Always on + smartest network + for your smartphone $\longrightarrow$ Circ,

Time + Circ, Cause

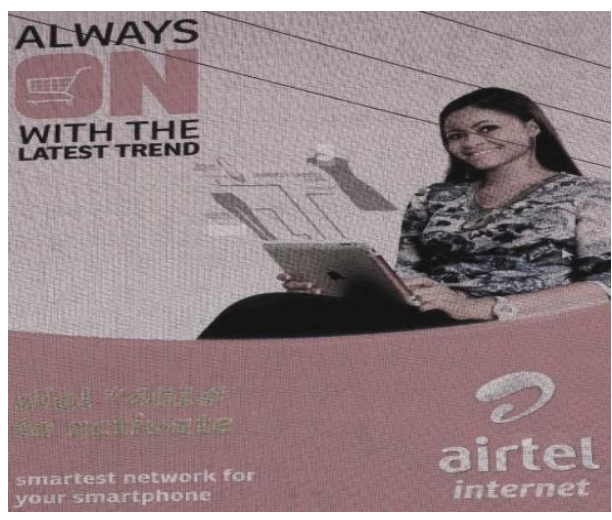

$A D 2$

The means, with the latest trends, as indicated in AD 2, harmonizes a picture of a young and smart woman with fashionable materials. The basket embedded in the letter $O$ of the lexeme $O N$ reflects a shopping tool. This suggests that most women do not handle the matter of shopping with levity. Airtel is the network that 
will assist consumers to locate changes and developments in the fashion. With Airtel, there is no point that one stresses herself in search of the current trends. Worries should be allayed; consumers using the internet supplied by Airtel are secured, being the perspectives of the Airtel team. This is because knowing the recent trends in the market has become Airtel's responsibility. The systemic structure, with the latest trends operates as the element of manner in the Circumstantial group.

$\mathrm{SD}=$ Always on + with the latest trend $\longrightarrow$ Circ, Time + Circ, Manner

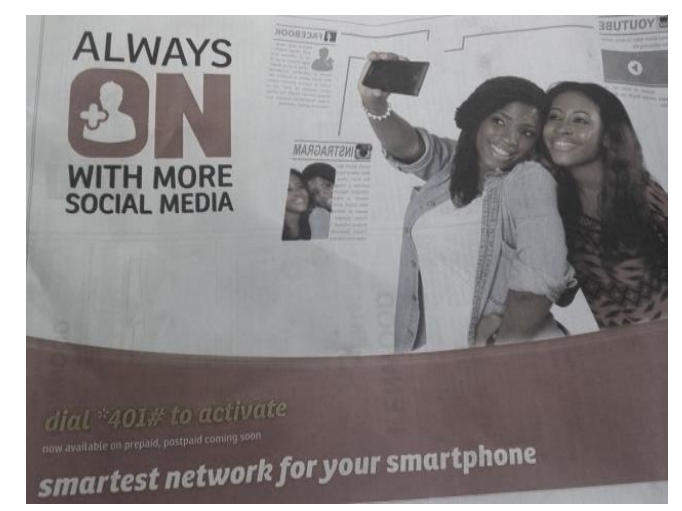

$A D 3$

AD 3 of the Always On series shows two young ladies with one of the ladies raising up her handset. These ladies are a probable symbol of the youthful exuberance in young ladies. The Internet is a medium where several opportunities are showcased for the users. This depends on one's eclectic sensationalism (Vettehen, Nuijten \& Beentjes, 2005; Uribe \& Gunter, 2007). The youth, one could suggest, are familiar and keen to using the Internet for a lot of things. The social media campaigns in the ad frame are the websites and the other Internet applications. Some of the social media are Facebook, Twitter, Instagram, Linkdin, WhatsApp, You-Tube, etc. The applications enable consumers to create and share contents (such as names, addresses, comments, opinions, statuses, pictures, videos, professions, match-making processes, etc.) one with another to participate in social networking (Halliday \& Webster, 2007). The availability of the social media offers vistas for consumers of common interest to load information about themselves in the media in order to construct relationships and create correlative connections. The Circumstantial structure is inclined to manner in the domain of purpose.

$\mathrm{SD}=$ Always on + with more social media $\longrightarrow$ Circ, Time + Circ, Manner 
Dalamu:

Analyzing Advertising Specimen within the Scope of Circumstantial Choices

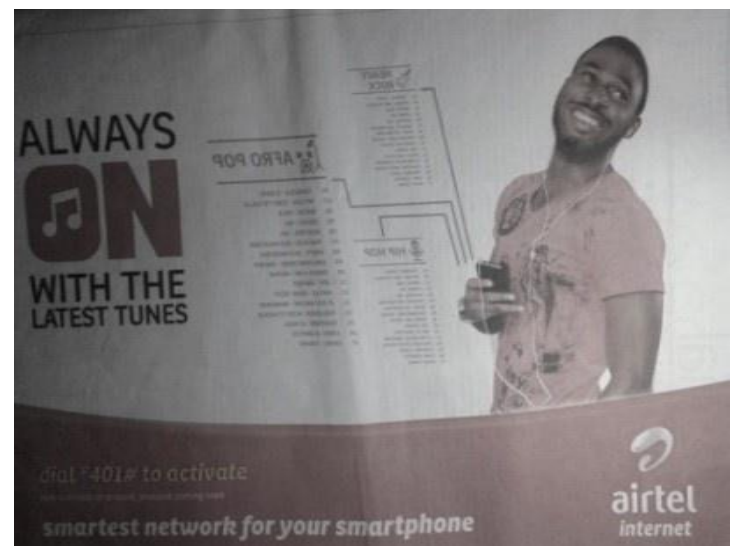

AD 4

AD 4 portrays the notion of music designated as the latest tunes. One can argue that music is food for the soul. In Shakespeare's Twelfth Night, it is also claimed that "If music be the food of love, play on, /Give me excess of it; that surfeiting, /The appetite may sicken, and so die" (Goodreads, n.d.). The author might further characterize musical tunes as being dynamic in melody, harmonious in tempo, and rhythmical with timbre and form. One of the musical symbols (beamed notes) is used on this representation. This symbol exhibits eight notes of shorter value equivalent to flags. One could remarks again that beamed notes are applied basically for melismatic (Greek: the singing of a single syllable of text while moving between several different notes in succession) singing. Music players irregularly utilize beam symbolic instruments to place emphasis on a particular rhythmic pattern (Estrella, 2015; Miller, n.d.). Above all, the importance of music in human life cannot be discarded with a wave of hand. This is because the satisfaction and excitement in music make pleasant vibes not only delightful to the soul, but also entertaining and thrilling.

Of a truth, hardly can one see an individual on earth that resists melodious musical tunes. Music, the writer could reiterate, is enjoyable and pleasant. Airtel advertisers seem to understand that perhaps one might try to escape the other phenomena propagated in the Always On ads. However, the provision of listening to music through the Airte/ network may become an irresistible impulse, and most especially for the young folks. The structure of the Circumstantial function is projected in the degree of manner.

$A D=$ Always on + with the latest tunes $\longrightarrow$ Circ, Time + Circ, Manner 


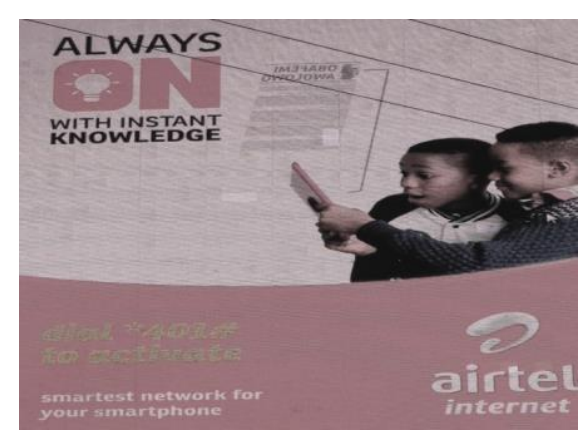

AD 5

Knowledge is power, as renowned aphorism, could be the motif behind the Airtel's attempt to provide an avenue for learning and knowledge acquisition in their network. The AD 5 reads Always On with instant knowledge. To avert stern criticisms, Airtel advertisers could have thought otherwise to enrich the minds of consumers with something educative. The intention is to let subscribers understand that their children including their parents could learn something worthwhile through the Airtel network; hence, they introduce a package of knowledge acquisition (Halliday \& Webster, 2016). The ad shows one of the two boys reading from the iPad with a surprise. Their actions demonstrate that the individuals perceive something uncommon in the network. Most parents may regulate their wards regarding what they consume from the Internet. Some parents and guardians could go an extra mile to monitor their children on Internet matters and other activities performed with handsets. To a large extent, parents and guardians counsel their children on the entities to consume and what not to consume. The instant knowledge provision that Airtel sells is a way of assisting the children to use the Internet for something more meaningful. This can build their intellectual capacity that will be commendable by their parents and guardians (Dalamu, 2017, in press). However, this is also a strategic means of attracting subscribers to the Airtel services. The Circumstantial structure propagates purpose in the declarative fragment.

$\mathrm{SD}=$ Always on + with instant knowledge $\longrightarrow$ Circ, Time + Circ, Manner

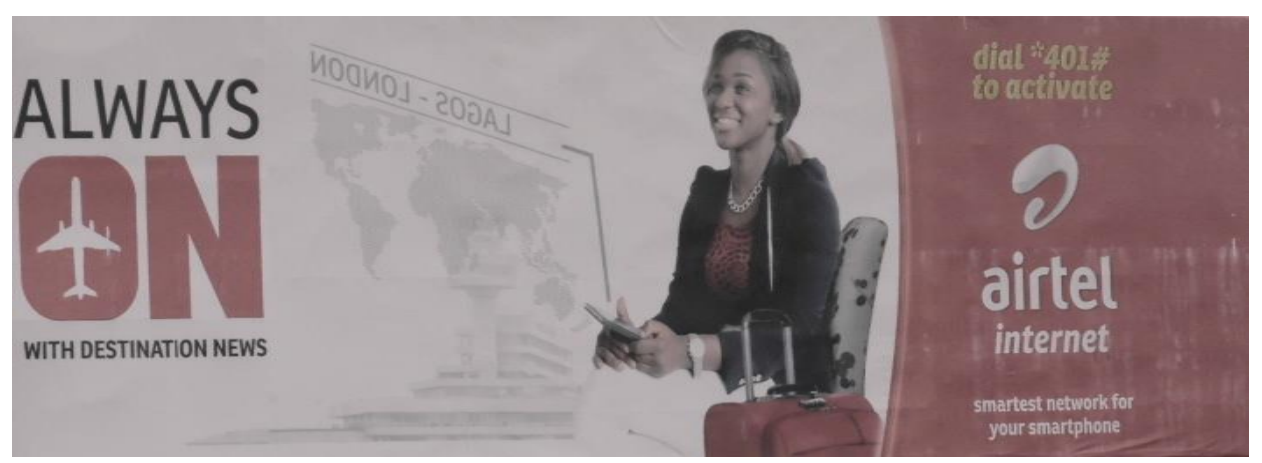

AD 6 
Dalamu:

Analyzing Advertising Specimen within the Scope of Circumstantial Choices

AD 6 reveals a contrastive paradigm, Lagos - London as the background of the ad on top of the world map. Travelling from Lagos to London, in recent times, is not by road but rather enrooted by air. The text $O N$ features the symbol of an aircraft which signals comfort of travelling by either a short trip or long journey. The stake of Airtel Nigeria is the claim that its management team has taken it upon themselves to provide all the needed news regarding travelling within and outside the shore of Nigeria to all Airtel consumers. The service that Airtel provided will enable the public to assess news concerning their destinations at any point in time wherever and whenever. The text Always on with destination news is complemented with a picture of a beautiful young lady operating a handset - which seemingly represents checking her destination news online; this is also applicable to all Airtel consumers. With destination news functions as purpose in the Circumstance of manner.

$\mathrm{SD}=$ Always on + with destination news $\longrightarrow$ Circ, Time + Circ, Manner

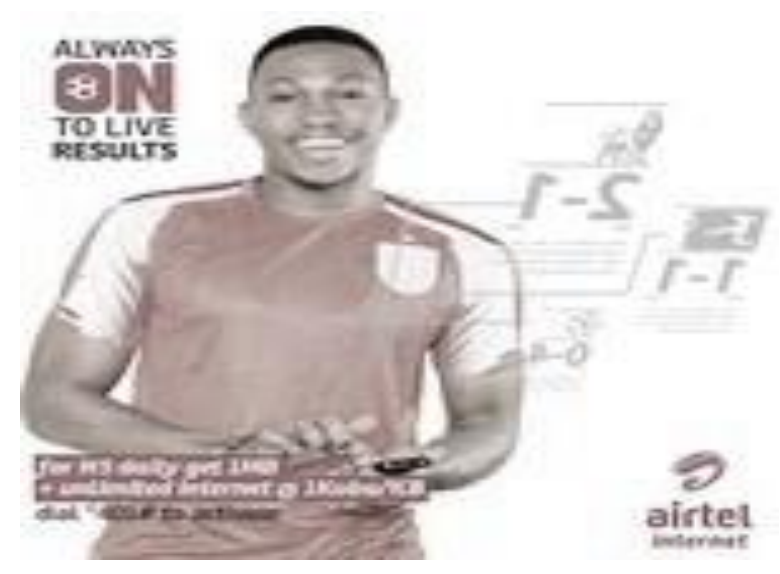

AD 7

The most pronounced subject observed in $A D 7$ is a young chap dressed up with an Arsenal-like jersey, though there is no Arsenal stamp on the jersey. The chap happily holds a handset in his hand checking something. It could be predicted that the chap is checking results of football matches in the Premier League games. This assumption comes to the fore through the background inversion of some results such as 2-1, 1-1, 0-4, etc. accompanied with the logo of the Premier League. The framework also shows Premier League in an inverted format in order to demonstrate the Paradigmatic panorama of the concept of Always On. It is indicative that Always on to live results portrays the availability of football live results through the Internet facility provided. The social background is seen as the Premier League does not suggest that other leagues could not be available to football enthusiasts. The ideological implication is that the majority of football fanatics in Nigeria mostly watch the Premiership (IProject, 2016). The league raises the ego of most Nigerians. Perhaps, the fanaticism of Nigerians about the league heightens their passions to feel that the league is much better 
than any other league in the world (Bankole, 2016). The ideological representation of the ad seems to demonstrate that all the other leagues' results locally and internationally, at amateur level and professional level could be accessed from the Airtel's internet network. Structurally, the Circumstance focuses role playing in the clause to signify the operational capacity of Always On.

$\mathrm{SD}=$ Always on + to live results $\longrightarrow$ Circ, Time + Circ, Role

\section{Conclusion}

The author has analyzed seven ads of the Airtel's Always On with alternating choices to influence the target audience. Each semiotic paradigm, elucidating a circumstantial choice, is associated with a symbolic element that visualizes the messages intended to the public. Young ladies, boys and little kids are used in the ads. By implication, that communication style suggests to the writer that the majority of the target audience belongs to those groups of people. The ads also contain semiotic paradigms with inverted models, which are applied as background details. The inverted detailed choices, in a way, represent additional messages. $A D 2$ has dresses and fashion materials as its background representing latest trends. The background of the AD 3 contains Facebook, Instagram and Youtube representing social media. There are genres of music serving as the background of AD 4 representing latest tunes. Obafemi Awolowo is applied as the background of AD 5, which seems to depict knowledge to students. AD 6 contains the world map with Lagos - London inscription portraying destination news to travelers. The last ad, AD 7 indicates some results of the Premier League in England as the background of the message representing football live results to its lovers.

The pivot of all the Always On ads indicates a point of departure of the sensitization. The goal which seems as the centrality of the messages of the ads is dial * $401 \#$ to activate. This is because the intention of the alternated paradigms is to persuade subscribers to buy the advertised goods and services. Therefore, the alternating devices of the ads of Airtel's Always On are sometimes created with the inverted textual-pictorial background as appealing elements to consumers. It is recommended that such structural creativity should be encouraged. Apart from the influence that the constructive choices could have on consumers; the word-play in different Circumstantial parameters could create much enlightenment for researchers on the means of systematizing linguistic facilities in order to produce meaning potential in communication. 
Dalamu:

Analyzing Advertising Specimen within the Scope of Circumstantial Choices

\section{References}

Adedun, E. \& Hammond, C. (2013). Semiotics analysis of selected billboard advertisements in Nigeria and Ghana. Lagos Notes and Records, 19(2), pp. 41-52.

Ambekar, A. (2009). Different types of advertising appeals. Retrieved from http://www.infojug.com/advertising-articles/types-of-advertising-appeals.html

Bankole, T. (2016). Football craze: Foreign leagues followership by Nigerians hits new heights on ESPN. Retrieved from

http://thenet.ng/2016/05/football-craze-foreign-leagues-followership-by-nigerianshits-new-heights-on-espn/

Bloor, T. \& Bloor, M. (2004). The Functional Analysis of English. Great Britain: Hodder Arnold.

Bloor, T. \& Bloor, M. (2013). The Functional Analysis of English. Abingdon: Oxon, Routledge.

Brown, K. \& Miers, P. (2009). The semiotics of gender based advertising. Retrieved from http://www.wikispaces.com\%2Ffile\%2Fview\%2FKristina\%2BBrown\%2BThe\%2B Semiotics\%2Bof\%2BGender\%2BBased\%2BAdvertising\%2B.doc

Butler, C. S. (2003). Structure and Function: A guide to three major structural-functional theories, Part I. Amsterdam/Philadelphia: John Benjamins

Chandler, D. (2012). Semiotics for beginners. Retrieved from wwaber.ac.uk/media/Documents/S4B/semiotic.html

Combe, I., Crowther, D. and Greenland, S. (2003). The semiology of changing brand image. Journal of Marketing and Entrepreneurship, 5(1), pp. 1-24.

Cook, G. (2001). The discourse of advertising. New York: Routledge.

Dalamu, T. O. (2017a). Institution's title and shibboleth: A construct of grammatical relationship in advertising plates. Journal of Language and Linguistic Studies, 13(1), pp. 260-282.

Dalamu, T. O. (2017b). A functional approach to advertisement campaigns in Anglo-Nigerian Pidgin. Studies in Linguistics, 44, p. 155-185. https://doi.org/10.17002/sil.44201707.155

Dalamu, T. O. (2017c). Nigerian children specimens as resonance of print media: What for? Communication, 11(2) (in press, December, 2017).

Dyer, G. (2005). Advertising as communication. London: Routledge.

Eggins, S. (2004). Introduction to systemic functional linguistics. London: Continuum.

Estrella, E. (2015). Music history 101. Retrieved from http://musiced.about.com/od/beginnerstheory/a/musicelements.html

Fontaine, L. (2013). Analyzing English Grammar: A systemic functional introduction. Cambridge: Cambridge University Press.

Fontaine, L., Bartlett, Tom \& O'Grady, Gerard (2013). Systemic Functional Linguistics: Exploring choice. Cambridge: Cambridge University Press.

Fowles, J. (1998). Advertising's fifteen basic appeals. Retrieved from http://www.cyberpat.com/shirlsite/education/essay2/jfowles.html 
Gee, J. P. (2011). An Introduction to discourse analysis: Theory and practice. New York: Routledge.

Glenberg, D. \& Rinck, M. (2007). Emotion simulation during language comprehension. Retrieved from http://www.cogsci.ucsd.edu/ coulson/Courses/200/Havas-Glenberg-Rinck_2007. pdf

Goodreads (n.d.). William Shakespeare quotes: Quatable. Retrieved from http://www.goodreads.com/quotes/3149-if-music-be-he-food-f-love-play-on-give Halliday, M. A. K. (1994). An introduction to functional grammar. Great Britain: Arnold. Halliday, M. A. K. \& Christian M. I. M. (2004). An Introduction to functional grammar. Great Britain: Arnold.

Halliday, M. A. K. \& Christian M. I. M. (2014). Halliday's introduction to functional grammar. Abingdon, Oxon: Routledge.

Halliday, M. A. K. \& Webster, Jonathan, J. (2003). Language of early childhood. New York and London: Continuum.

Halliday, M. A. K. \& Webster, Jonathan, J. (2005a). On grammar. New York and London: Continuum.

Halliday, M. A. K. \& Webster, Jonathan, J. (2005b). Computational and quantitative studies. New York and London: Continuum.

Halliday, M. A. K. \& Webster, Jonathan, J. (2007). Language and society. New York and London: Continuum.

Halliday, M. A. K. \& Webster, Jonathan, J. (2009). Continuum companion to Systemic Functional Linguistics. New York and London: Continuum.

Halliday, M. A. K. \& Webster, Jonathan, J. (2016). Aspects of language and learning. Heldelberg: Springer-Verlag.

Hollis, N. (2010). Emotion in advertising: Pervasive, yet misunderstood. Retrieved from http://www.millwardbrown.com/docs/default-source/insight-documents/points-of-vi ew/MillwardBrown_POV_EmotionInAdvertising.pdf

IProject (2016). An Assessment on the effects of English Premier League Matches showing on STV on Nigeria youths. Retrieved from http://www.iproject.com.ng/education/final-year-project-topics/an-assessment-on-t he-effects-of-english-premier-league-matches-showing-on-dstv-on-nigeria-youths /project-topics

Khan, R. \& S. Sindhu, S. (2015). An Investigation of advertising appeal on Consumer response in service advertising. Management Studies and Economic Systems, 2(1), pp. 39-50.

Leech, G. (1966). English in advertising: A linguistic study of advertising in Great Britain. London: Longman.

Long-Yi, L. (2011). The impact of advertising appeals and advertising spokespersons on advertising attitudes and purchase intentions. African Journal of Business Management, 5(21), pp. 8446-8457. https://doi.org/10.5897/AJBM11.925.

Magalhães, I. (2005). Critical discourse analysis and the semiotic construction of Gender identities. https://doi.org//10.1590/S0102-44502005000300011 
Dalamu:

Analyzing Advertising Specimen within the Scope of Circumstantial Choices

Martin J. (1992). English text: System and structure. Amsterdam: John Benjamin. Matthiessen, Christian M.I.M., Teruya, Kazuhiro \& Lam, Marvin (2010). Key terms in Systemic Functional Linguistics. London and New York: Continuum.

Matsumoto, D. (n.d.). The origin of universal human emotions. Retrieved from http://davidmatsumoto.com/content/NG\%20Spain\%20Article_2_.pdf

Miller, S. J. (n.d.). Characteristics of music. Retrieved from http://www.ehow.com/info_8475291_10-characteristics-music.html

Mohanan, R. (2014). Advertising appeals. Retrieved from http://www.academia.edu/3981460/Advertising_Appeals

Myers, G. (1994). Words in ad. New York: Oxford University Press.

O'grady, W., Dobrovolsky, M., \& Aronoff., M. (1991). Contemporary linguistics: An introduction. New York: St. Martin's Press.

Opeibi, B. O. (2009). Discourse, politics and the 1993 presidential election campaigns in Nigeria. Lagos: Nouvelle Communications Limited.

Patidar, M. (2012). Advertising appeals. Retrieved from http://www.enotesmba.com/2012/07/mba-notes-advertising-appeals.html

Plutchik, R. (2001). The Nature of Emotion. American Scientists, 89, pp. 344-350.

Ravelli, L. \& Davies, M. (ed.) (1992). Advances in systemic linguistics: Recent theory and practice. London: Continuum.

Ravelli, L. (2000). Getting started with functional analysis of texts. In Unsworth, L. (ed.), Researching Language in Schools and Communities, pp. 27-63. London: Continuum.

Stone, R. (2000). A semiotic analysis of four designer clothing advertisements. Retrieved from http://www.aber.ac.uk/media/Students/rbs9701.html

Stubbs, M. (2002). Computer-assisted texts and corpus analysis: Lexical cohesion and communicative competence. In Schiffrin, D., Tannen, D., and Hamilton, H. (ed.), The handbook of discourse analysis, pp. 304-320. New York: Blackwell.

Thompson, G. (2004). Introducing functional grammar. Great Britain: Hodder Arnold.

Thompson, G. (2014). Introducing functional grammar. Abingdon, Oxon: Routledge.

Uribe, R., \& Gunter, B. (2007). Are sensational news stories more likely to trigger viewers emotions than non-sensational news stories?: A content analysis of British TV news. European Journal of Criminology, 22(2), pp. 207-228. https://doi.org//10.1177/0267323107076770

Vettehen, P. H., Nuijten, K., \& Beentjes, J. (2005). News in an age of competition: The case of sensationalism in Dutch Television news, 1995-2001. Journal of Broadcasting \& Electronic Media, 49(3), 282-295. https://doi.org//10.1207/s15506878jobem4903

Williamson, J. (1978). Decoding advertising: Ideology and meaning in advertising. New York: Marion Boyars.

Yule, G. (1985). The study of language. Cambridge: Cambridge University Press. 